\title{
BMJ Open Adolescent time use and mental health: a cross-sectional, compositional analysis in the Millennium Cohort Study
}

\author{
Andrew J Atkin (iD , ${ }^{1}$ Jack R Dainty (D) , ${ }^{2}$ Dorothea Dumuid (D) , ${ }^{3}$ Elli Kontostoli (D) , 1 \\ Lee Shepstone, ${ }^{2}$ Richard Tyler (D) , ${ }^{4}$ Robert Noonan (D) , \\ Cassandra Richardson (D), ${ }^{6}$ Stuart J Fairclough (i) ${ }^{4}$
}

To cite: Atkin AJ, Dainty JR, Dumuid D, et al. Adolescent time use and mental health: a cross-sectional, compositional analysis in the Millennium Cohort Study. BMJ Open 2021;11:e047189. doi:10.1136/ bmjopen-2020-047189

- Prepublication history and additional supplemental material for this paper are available online. To view these files, please visit the journal online (http://dx.doi.org/10.1136/ bmjopen-2020-047189).

Received 20 November 2020 Accepted 20 August 2021
Check for updates

(C) Author(s) (or their employer(s)) 2021. Re-use permitted under CC BY-NC. No commercial re-use. See rights and permissions. Published by BMJ.

For numbered affiliations see end of article.

Correspondence to

Dr Andrew J Atkin;

A.Atkin@uea.ac.uk

\section{ABSTRACT}

Objective To examine the association of 24-hour time-use compositions with mental health in a large, geographically diverse sample of UK adolescents.

Design Cross-sectional, secondary data analysis. Setting Millennium Cohort Study (sixth survey), a UKbased prospective birth cohort.

Participants Data were available from 4642 adolescents aged 14 years. Analytical samples for weekday and weekend analyses were $n=3485$ and $n=3468$, respectively (45\% boys, $85 \%$ white ethnicity).

Primary and secondary outcome measures Primary outcome measures were the Strengths and Difficulties Questionnaire (SDQ, socioemotional behaviour), Mood and Feelings Questionnaire (MFQ, depressive symptoms) and Rosenberg Self-Esteem Scale (RSE, self-esteem). Behavioural exposure data were derived from 24-hour time-use diaries.

Results On weekdays, participants spent approximately $54 \%$ of their time in sleep, $3 \%$ in physical activity, $9 \%$ in school-related activities, $6 \%$ in hobbies, $11 \%$ using electronic media and $16 \%$ in domestic activities. Predicted differences in SDQ, MFQ and RSE were statistically significant for all models (weekday and weekend) that simulated the addition or removal of 15 min physical activity, with an increase in activity being associated with improved mental health and vice versa. Predicted differences in RSE were also significant for simulated changes in electronic media use; an increase in electronic media use was associated with reduced self-esteem. Conclusion Small but consistent associations were observed between physical activity, electronic media use and selected markers of mental health. Findings support the delivery of physical activity interventions to promote mental health during adolescence, without the need to specifically target or protect time spent in other activities.

\section{INTRODUCTION}

The global adolescent population, estimated at 1.2 billion, is now larger than at any point in our history and represents approximately $16 \%$ of the global population. 'Accordingly, research and policy activity to support the biological, social, emotional and behavioural development of this population has grown substantially in recent years. ${ }^{2-4}$ Part of this
Strengths and limitations of this study

- The large, geographically and demographically diverse sample and the assessment of multiple mental health outcomes using well-established, widely tested instruments.

- Use of compositional data analysis of multiple behavioural exposures, which reflects that behaviour change inherently entails the reallocation of time between different domains of behaviour.

- The cross-sectional design which precludes causal inference.

- The susceptibility of time-use diaries to recall and social desirability bias.

- Analyses were based on a single day of assessment, which may not have been representative of typical behaviour patterns.

wider movement has been a particular focus on mental health during adolescence, consistent with evidence that first diagnosis of a mental disorder often occurs during this period. ${ }^{5-7}$ Surveillance data on adolescent mental health remain limited, but there is evidence of increasing prevalence of some conditions in recent years and substantial growth in demand for counselling and specialist mental health services. ${ }^{8-11}$ Recent data from the Mental Health of Children and Young People survey, for example, indicated that between 1999 and 2017, the prevalence of having an emotional disorder (including anxiety and depression) increased from $4.3 \%$ to $5.5 \%$ in children aged $5-15$ years. ${ }^{12}$ From the same survey, cross-sectional data collected in 2017 showed that just over $10 \%$ of children in this age group had low self-esteem. ${ }^{12}$ Interpretation of secular trend data on the prevalence of mental disorders in young people is complicated by a host of methodological, diagnostic and social factors, but it remains clear that a considerable proportion of the child and adolescent population experience 
mental ill health. A clearer understanding of factors that might predispose or protect children from mental health disorders will help in the development of preventative policies and practice.

A growing body of evidence indicates a role for health behaviours, such as sleep and physical activity, in the prevention of mental health disorders. ${ }^{13-18}$ A recent US study, for example, found that over 1 year, sleep duration of less than 6 hours a night was associated with increased risk of anxiety disorders in adolescents aged 11-17 years. ${ }^{16}$ This study adjusted for selected social and demographic covariates but did not account for other health behaviours, such as physical activity or sedentary behaviour. Given the finite time available each day, an increase in any behaviour (eg, sleep) can only be achieved through a concomitant reduction in time allocated to one or more other activities (eg, TV viewing). The nature of such reallocations has potentially important implications for health. The mental health benefits of increasing sleep duration, for example, may not be realised if they come at the expense of reduced physical activity, which is also positively associated with some mental health outcomes. Greater recognition of the complex interplay between multiple behaviours and health has led to the adoption of sophisticated and more appropriate statistical methods and the establishment of new research networks to take the field forward. ${ }^{19-24}$ This movement is reflected in new public health recommendations that provide guidance on the optimal composition of the entire (24hours) day, rather than focussing on a single behaviour, such as physical activity or sleep. ${ }^{25} 26$

Previous research into the association of time-use composition with mental health in young people has focused predominantly on health-related quality of life, captured within global measures or social/emotional health subscales. ${ }^{27-29}$ Studies using cluster analysis to identify subgroups with distinct behavioural profiles have indicated that a lifestyle characterised by low physical activity and/or moderate to high sedentary behaviour was associated with poorer quality of life. ${ }^{2830}$ In contrast, Fairclough et $a l^{29}$ observed no differences in psychosocial quality of life for simulated substitutions between accelerometerassessed sitting, light and moderate to vigorous intensity physical activity (MVPA) during the school day. One study to date has examined the association of time use with proxy-reported Strengths and Difficulties Questionnaire $(\mathrm{SDQ})$ scores, observing that substituting time into MVPA from sleep, light intensity activity or sedentary time was associated with better mental health. ${ }^{31}$ The relative lack of previous research on this topic, combined with the conflicting findings of what little evidence does exist, highlights the need for further research in this field. Therefore, the objective of this study was to examine the cross-sectional associations between adolescents' time-use composition and selected markers of mental health and well-being.

\section{METHOD}

\section{Sample and data collection}

Data are from the Millennium Cohort Study (MCS), an observational cohort study of the social, economic and health-related circumstances of children born in the UK between September 2000 and January 2002. ${ }^{32}$ The MCS is nationally representative and 18552 families (18 818 children) were recruited in the first sweep. The sample was augmented with a further 701 children (692 families) born in the same period who had been missed previously, taking the total sample to 19519 . To date, there have been six waves of assessment (age 9 months, $3,5,7,11$ and 14 years). This cross-sectional analysis uses data from the sixth wave of assessment (MCS6; data collection: January 2015-April 2016), conducted when participants were aged 14 years. A total of 15415 families were contacted for participation in MCS6; 11884 participants from 11726 families provided partial or complete data. The current study uses anonymised, publicly available data obtained from the UK Data Service (https://beta.ukdataservice.ac. uk/datacatalogue/series/series?id=2000031) .

\section{Patient and public involvement}

The research question for this analysis was formulated by the authors (no patient involved). The content and methodology of the sixth sweep of MCS were informed by extensive development work to ensure relevance, participation and engagement among participants and their families. Full details are provided in the MCS Sixth Sweep technical report. ${ }^{33}$

\section{Assessment of time use}

All participants from Wales, Scotland and Northern Ireland and approximately $80 \%$ of participants from England were invited to complete time-use diaries for two 24-hour periods (one week day and oneweekend day). Days were selected at random by computer-assisted personal interview software. The English sample was restricted due to limitations on the number of activity monitors available, which were deployed alongside the time-use diary. Only diary data are used for the current analysis. The diary was available in three formats: online (for completion on a desktop, laptop or netbook); using an app (for completion on a mobile phone or tablet); or on paper. Sixty-four per cent of participants selected the app diary format; $29 \%$ used the online version; and $7 \%$ used the paper diary. ${ }^{33}$

For each day of assessment, participants recorded what they did from 04:00 to 04:00 the following day in $10 \mathrm{~min}$ timeslots. Participants also recorded where they were, who they were with and how much they liked each activity, but these data are not considered here. The primary activity for each time slot was selected from a list of 44 predefined activity codes, nested within 12 categories. Categories included 'sleep and personal care', 'school, homework and education', 'social time and family time' and 'internet, TV and digital media'. ${ }^{34}$ Due to the differing demands/opportunities afforded by being 
at school during the week, weekday and weekend data were analysed separately. For the weekday data, activity codes were collapsed into six mutually exclusive activity sets (see online supplemental material): (1) sleep; (2) physical activity; (3) school-related activities; (4) hobbies and socialising; (5) electronic media; and (6) domestic, personal care and work-related activities. Weekend data were collapsed into five sets, omitting the school-related activities group. The five/six sets capture the entirety of participant's daily time use ( 24 hours or $1440 \mathrm{~min}$ ). Note that the sleep component represented all sleep occurring between 04:00 and 04:00. Therefore, it does not necessarily represent a full overnight sleep and may incorporate naps taken during the day.

Diaries with missing data $(10 \mathrm{~min}$ slots with no activity indicated) were excluded from the analysis, as were those with no entries for 'sleep' or 'domestic, personal care and work-related activities' (which included eating and getting dressed); these were deemed to be unreliable accounts of a complete day's activity. Zero values in any of the activity sets would preclude the use of compositional analysis, as log ratio coordinates cannot be applied to zero values. ${ }^{35}$ Consistent with previous work using time-use data, zeros were replaced with small values of less than $10 \mathrm{~min}$, drawing time from the other activity sets. ${ }^{35} 36$

\section{Mental health}

Three outcomes related to adolescent mental health were used in the analysis. Socioemotional behaviour was assessed using the SDQ, V.P4-17, completed by the parent or guardian. ${ }^{37}$ The SDQ comprises 25 items relating to five subscales of five items each (difficulties subscales: emotional problems, conduct problems, hyperactivity/ inattention and peer relationship problems; strengths subscale: prosocial behaviour). Answers are provided with reference to the previous 6 months and response options are 'not true', 'somewhat true' and 'certainly true'. Example items are 'Often has temper tantrums or hot tempers' and 'Often unhappy, down-hearted or tearful'. A total difficulties score, derived as the sum of responses on the four difficulties subscales, was used in the analysis, consistent with previous research. ${ }^{38}{ }^{39}$ Higher scores indicate greater socioemotional difficulty. Depressive symptomology was assessed using the short-version (13-item) Mood and Feelings Questionnaire (MFQ), completed by the participant. ${ }^{40}$ Answers are given with reference to the previous 2 weeks. Response options are 'not true', 'sometimes' and 'true'. Example items are 'I felt miserable or unhappy' and 'I didn't enjoy anything at all'. MFQ is scored as the sum of responses to all items, with higher scores suggesting more severe depressive symptoms. Global self-worth was self-reported using the five positive items from the Rosenberg Self Esteem Scale (RSE). ${ }^{41}$ Response options are 'strongly agree', 'agree', 'disagree' and 'strongly disagree'. Example item is 'On the whole, I am satisfied with myself'. A total score, derived as the sum of responses to all items, was used in the analysis. For consistency with other outcomes, responses were recoded such that higher scores were indicative of lower self-esteem.

\section{Covariates}

Covariates were selected on the basis of previous research indicating that they may confound associations between exposure and outcome variables used in the current study. ${ }^{151631}$ The following constructs were selected: age, sex, adiposity (measured height and weight used to derive body mass index (BMI) category ${ }^{42}$ : underweight/normal, overweight or obese) and equivalised family income (parent reported: <£20800 annually, £20800-£31300 annually, >£31 200 annually, missing or do not know).

\section{Statistical analysis}

Analyses were conducted using $\mathrm{R}$ open-source software (www.r-project.org) and the compositions and zCompositions packages for the analysis of compositional data (V.1.40-2) ${ }^{43}$ Demographic and anthropometric characteristics of the analytical sample are presented as frequencies and percentages, means with SDs or medians with IQRs as appropriate. Characteristics of those included/ excluded from the analytical sample were compared using Student's t-tests or $\chi^{2}$ tests. Time ( $\mathrm{min} /$ day) spent in each behavioural set is summarised for the raw time-use data (that which retained zero values) using median and IQR. For the imputed time-use compositions (those in which zeros were replaced with small non-zero values, as described previously), time in each behavioural set is presented as compositional means (geometric mean of each behaviour, linearly adjusted to collectively sum to $1440 \mathrm{~min})$. Summary statistics are presented separately for weekdays and weekend days. Due to the distribution of the health outcome data, associations between time use composition and mental health markers were examined using negative binomial regression. ${ }^{44}$ Time-use compositions were expressed as sets of isometric log ratio (ILR) coordinates ( $\mathrm{R}$ compositions, default ilr() transformation). The five-part and six-part compositions for weekend and weekday time uses were expressed via four and five sets of ILR coordinates, respectively. All models were adjusted for age, sex, weight status and family income. In preliminary analyses, models were additionally adjusted for ethnicity and maternal education. However, these variables demonstrated weak, non-significant associations with the outcomes and were subsequently dropped in the interests of model parsimony. Models were checked to ensure assumptions were not violated. Following procedures outlined in Dumuid et al, ${ }^{19}$ we subsequently conducted compositional isotemporal substitution analyses to model the influence of reallocating fixed time durations (15 min) between pairs of behaviour sets on each of our mental health outcomes. Models were adjusted for the same covariates as described previously and assessed for compliance with relevant statistical assumptions. When this model is subsequently used (in time reallocation of diary activities) to predict new values of the outcome, the predicted data are in log units, which 
makes it incompatible for mathematical operators such as subtraction to be used for estimation of differences. It is therefore necessary to transform the predicted values back into the original units (by taking the exponential) before estimating the differences in outcome due to time reallocation. In post hoc analyses, we explored the shape of the association between behaviour reallocations of differing duration and selected outcomes. Specifically, we modelled predicted differences in SDQ, MFQ and Rosenberg scores for reallocations of -30 to $+30 \mathrm{~min}$ ( $15 \mathrm{~min}$ increments, weekday data) or -20 to $+20 \mathrm{~min}$ ( $10 \mathrm{~min}$ increments, weekend data) between physical activity and the mean of all remaining behavioural sets. In addition, we modelled predicted differences in MFQ and Rosenberg scores for reallocations of -30 to $+30 \mathrm{~min}$ ( $15 \mathrm{~min}$ increments, weekday data) or -20 to $+20 \mathrm{~min}$ ( $10 \mathrm{~min}$ increments, weekend data) between electronic media and the mean of all remaining behavioural sets. Sets were combined for this analysis as the associations observed for paired reallocations between physical activity/electronic media and individual sets were highly consistent in direction and magnitude. The Generalised Linear Models that are used in the analysis, take the log of the outcome data before performing a regression with the explanatory variables. Regression estimates (and associated standard errors) are presented graphically for ease of interpretation.

\section{RESULTS}

Data were available from 8625 diaries (person-days), obtained from 4642 participants. Of these, 1679 diaries were excluded due to missing data or non-reporting of sleep or domestic/personal care activities. The analytical samples for weekday and weekend analyses were $n=3485$ (29.3\% of MCS6 participants) and n=3468 (29.2\% of MCS6 participants), respectively. Characteristics of participants included in the weekday analyses are presented in table 1. Overall, the weekday sample was $13.8(0.5)$ years of age, $45 \%$ male and predominantly white ethnicity $(85 \%)$. There were no differences in the demographic or anthropometric characteristics of the weekday and weekend analytical samples. Compared with those whose diaries did not meet our inclusion criteria (1679 diaries from $\mathrm{n}=1238$ participants), the analytical sample on average had a lower BMI (included: 21.2, excluded: 21.6; $\mathrm{p}=0.014$ ), were more likely to be of white ethnicity (included: $85 \%$ white, excluded: $76 \%$ white; $\mathrm{p}<0.001$ ) and came from families with higher income (included: $31 \%$ highest quintile, excluded: $19 \%$ highest quintile; $\mathrm{p}<0.001)$.

Time spent in each of the behavioural sets is presented in table 2. Compositional means indicated that on weekdays, participants spent approximately $54 \%$ of their time in sleep, $3 \%$ in physical activity, $9 \%$ in school-related activities, $6 \%$ in hobbies, $11 \%$ using electronic media and $16 \%$ in domestic activities. Corresponding figures for the
Table 1 Participant characteristics (weekday sample; values are mean (SD) unless stated otherwise)

\begin{tabular}{lll}
\hline & \multicolumn{2}{l}{ Weekdays ( $\mathbf{n = 3 4 8 5 )}$} \\
\hline Demographics & & \\
\hline Sex, $\mathrm{n}(\%$ male) & 1561 & $(45)$ \\
\hline Age (years) & 13.8 & $(0.5)$ \\
\hline BMI (kg/m $\left.{ }^{2}\right)$ & 21.2 & $(4)$ \\
\hline Ethnicity (white, $\mathrm{n}(\%))$ & 2951 & $(85)$ \\
\hline Family income (quintile, $\mathrm{n}(\%))$ & & \\
\hline First (lowest) & 327 & $(9)$ \\
\hline Second & 436 & $(13)$ \\
\hline Third & 686 & $(20)$ \\
\hline Fourth & 958 & $(28)$ \\
\hline Fifth (highest) & 1075 & $(31)$ \\
\hline Country, $\mathrm{n}$ (\%) & & \\
\hline England & 2119 & $(61)$ \\
\hline Scotland & 506 & $(15)$ \\
\hline Wales & 486 & $(14)$ \\
\hline Northern Ireland & 374 & $(11)$ \\
\hline Outcomes, median (IQR) & & \\
\hline SDQ & 6 & $(3.0-9.0)$ \\
\hline MFQ & 17 & $(14.0-21.0)$ \\
\hline RSE & 10 & $(7.0-10.0)$ \\
\hline
\end{tabular}

Weekend analysis, $n=3468$.

BMI, body mass index; IQR, inter-quartile range; MFQ, Mood and Feelings Questionnaire; RSE, Rosenberg Self-Esteem Scale; SD, standard deviation; SDQ, Strengths and Difficulties Questionnaire.

weekend were $56 \%$ (sleep), $2 \%$ (physical activity), $10 \%$ (hobbies), 16\% (electronic media) and 17\% (domestic).

Preliminary analyses indicated that after adjustment for age, sex, weight status and family income, the ILR coordinates for time-use composition were significantly associated with each of the outcome variables ( $p$ values for ILR coordinates: $\mathrm{SDQ}$, weekday $\mathrm{p}=0.018$, weekend $\mathrm{p}<0.001$; $\mathrm{MFQ}$, weekday $\mathrm{p}<0.001$, weekend $\mathrm{p}=0.023$; RSE weekday $\mathrm{p}<0.001$, weekend $\mathrm{p}<0.001)$. Compositional isotemporal substitution analyses were conducted to simulate the association with each outcome of reallocating $15 \mathrm{~min}$ between pairs of behavioural sets; results are presented in table 3 (weekdays) and table 4 (weekend), respectively.

For all three outcomes, models that simulated the addition or removal of time from physical activity were statistically significant, with the addition of physical activity being associated with improved mental health and vice versa. The only exception to this trend was for MFQ and the substitution of time from domestic activities or hobbies into physical activity at the weekend, wherein the upper bound of the 95\% CI marginally overlapped zero in both cases. Predicted differences were generally larger for the weekend analysis than the weekday analysis but remained small at less than 0.3 of a unit of the outcome in all instances. 
Table 2 Descriptive characteristics of time-use compositions (min/day)

\begin{tabular}{|c|c|c|c|c|c|c|}
\hline \multirow[b]{3}{*}{ Sleep } & \multicolumn{4}{|c|}{$\begin{array}{l}\text { Raw composition } \\
\text { Median (IQR) }\end{array}$} & \multicolumn{2}{|c|}{$\begin{array}{l}\text { Imputed composition } \\
\text { Compositional mean* }\end{array}$} \\
\hline & \multicolumn{2}{|c|}{ Weekday } & \multicolumn{2}{|c|}{ Weekend } & \multirow{2}{*}{$\begin{array}{l}\text { Weekday } \\
779.8\end{array}$} & \multirow{2}{*}{$\begin{array}{l}\text { Weekend } \\
800.8\end{array}$} \\
\hline & 550 & $(500-610)$ & 630 & (550-690) & & \\
\hline Physical activity & 40 & $(0-110)$ & 30 & $(0-120)$ & 42.2 & 23.0 \\
\hline School-related & 370 & $(0-420)$ & NA & & 135.3 & NA \\
\hline Hobbies & 90 & (20-200) & 180 & $(60-320)$ & 85.2 & 144.9 \\
\hline Domestic & 180 & (120-250) & 200 & $(130-300)$ & 235.6 & 245.2 \\
\hline
\end{tabular}

Weekday, $n=3485$; weekend $n=3468$.

${ }^{*}$ Geometric mean adjusted to sum to $1440 \mathrm{~min} /$ day.

IQR, inter-quartile range; NA, not applicable.

For the SDQ outcome, there were no statistically significant predicted differences for reallocations that did not include physical activity. For the Rosenberg outcome, all reallocations that included electronic media were statistically significant in the weekday data, with a reduction in time spent using electronic media associated with better mental health. This pattern was partially repeated in the weekend data, except that models simulating the reallocation of time from sleep and domestic activities into electronic media were non-significant. All predicted differences were less than 0.1 units. For MFQ and in the weekday data only, reallocations between electronic media/sleep and electronic media/domestic activities were statistically significant, with a reduction in time spent using electronic media associated with better mental health.

Predicted differences in SDQ, MFQ and Rosenberg scores for a range of time reallocations to/from physical activity are presented in figure 1 . Consistent with the main analysis, figures show that simulated increases in physical activity were associated with reduced scores (negative predicted difference, better health) on each of the outcomes, while simulated reductions in physical activity were associated with higher outcome scores (positive predicted difference, worse health). In all scenarios, there was evidence of a curvilinear association, such that a modelled reduction in physical activity produced larger predicted differences in the outcomes than a modelled increase in physical activity of comparable duration. Predicted differences in MFQ and Rosenberg scores for a range of time reallocations to/from electronic media use are presented in figure 2. Simulated increases in electronic media use were associated with increased scores (positive predicted difference, worse health) on each of the outcomes, while simulated reductions in electronic media use were associated with lower outcome scores (negative predicted difference, better health). In the weekday data (figure 2A,C), the shape of the association appeared approximately linear throughout the range of reallocations tested. In the weekend data (figure 2B,D), there was evidence of slight deviation from linearity, wherein a modelled increase in electronic media use produced larger predicted differences in the outcomes than a modelled reduction in electronic media use of comparable duration.

\section{DISCUSSION}

In this large sample of UK adolescents, we found that simulated increases in physical activity were beneficially associated with socioemotional health, while comparable increases in electronic media use were adversely associated with depressive symptoms and self-esteem. Associations were largely consistent between week and weekend days, but remained small in magnitude across all behaviours and outcomes. Findings highlight a potential role for physical activity in supporting the socioemotional health of adolescents and provide insight into the possible content and timing of behaviour change interventions.

A simulated reallocation of $15 \mathrm{~min}$ from sleep, hobbies, electronic media use, school-related or domestic activities to physical activity was associated with better socioemotional health, reduced depression symptomology and improved self-esteem. This is consistent with previous research by Carson et $a l^{31}$ who modelled the impact on SDQ scores of substituting time between sleep, sedentary time, and light and moderate to vigorous intensity physical activity measured by accelerometry. More broadly, our findings corroborate existing evidence, both observational and experimental, that physical activity may have a role in the prevention and treatment of mental ill health in young people. ${ }^{45}$ The association of physical activity with all outcomes studied here was consistent in direction and magnitude for reallocations across all other behavioural domains, suggesting that the benefit of physical activity is universal and not dependent on a reduction in any specific behaviour or group of behaviours. It should be acknowledged, nonetheless, that the associations were small in magnitude, perhaps indicating that physical activity alone may not be sufficient to bring about clinically meaningful benefits in the specific health markers examined here. Further research that incorporates other domains of 


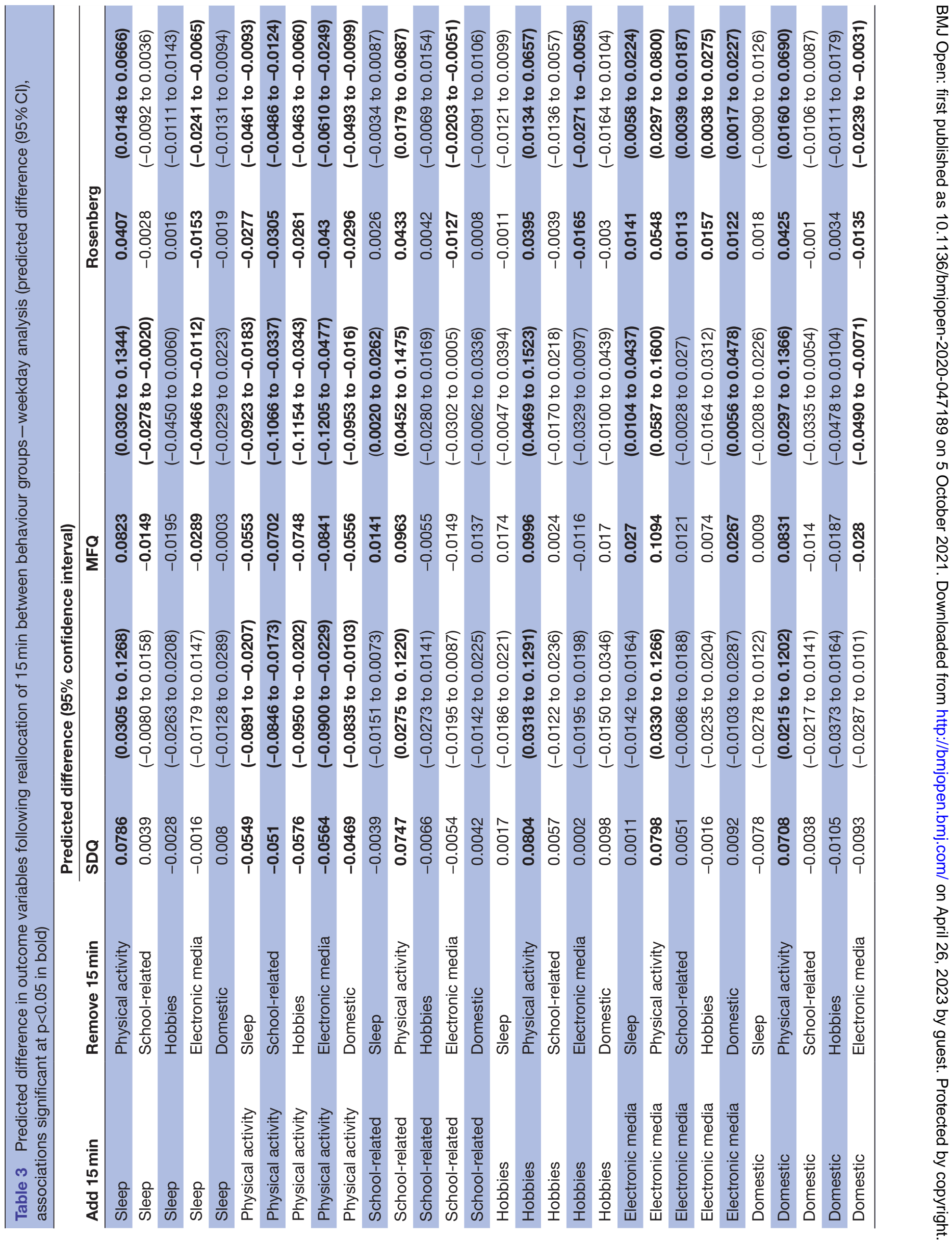




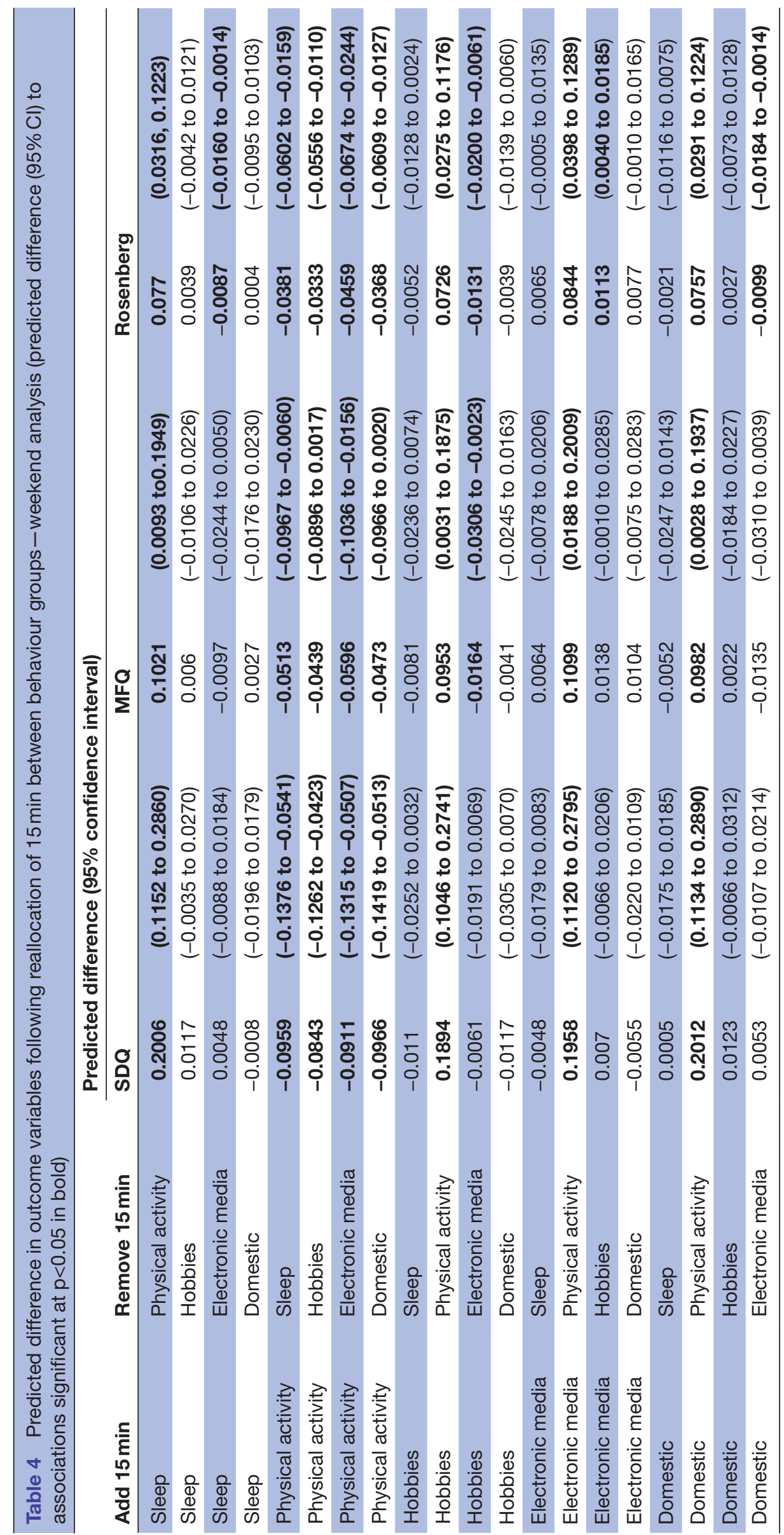




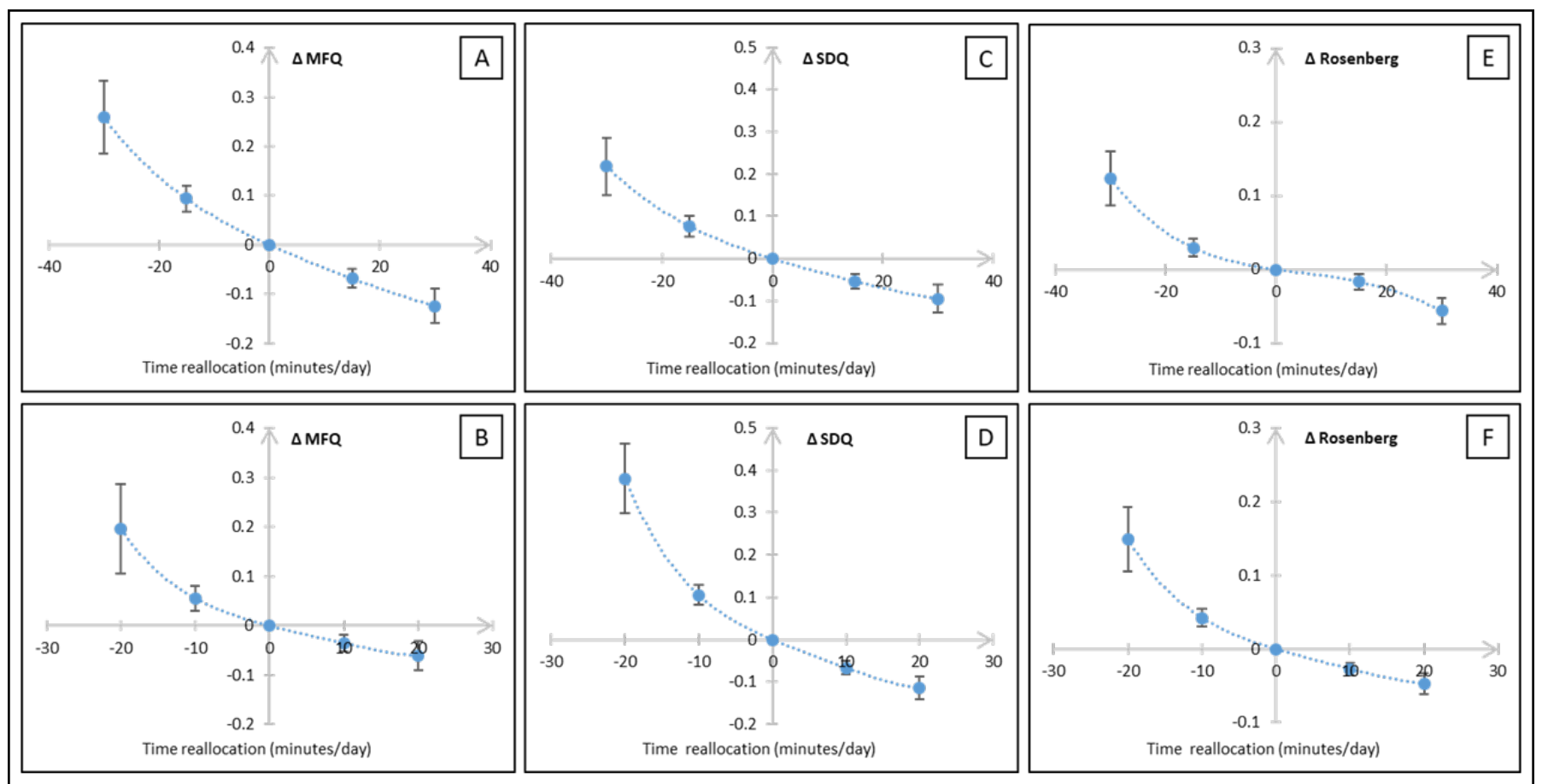

Figure 1 Predicted difference in Strengths and Difficulties Questionnaire, Mood and Feelings Questionnaire and Rosenberg Self Esteem Questionnaire scores with selected time reallocations to/from physical activity. MFQ, Mood and Feelings Questionnaire; SDQ, Strengths and Difficulties Questionnaire. Weekday data: panels A, C, E. Weekend data: panels B, D, F. Descriptive statistics (median (inter-quartile range)): MFQ: 17.0 (14.0, 21.0); SDQ: 6.0 (3.0, 9.0); Rosenberg: 10.0 (7.0, 10.0). Models adjusted for age, sex, body mass index and family income. Data points are predicted differences in the outcome \pm standard error. Interpretation: Points plotted to the left of the Y-axis denote predicted differences in the outcome for a specified reduction in physical activity. Points plotted to the right of the Y-axis denote predicted differences in the outcome for a specified increase in physical activity.

physical activity, such as intensity or activity type, alongside duration, will be beneficial in establishing the direction and magnitude of the association with mental health. This point notwithstanding, and given the plethora of other known benefits of physical activity, our findings support the promotion of physical activity as part of a wider package of measures for the benefit of emotional and behavioural health during adolescence.

Across the range of behavioural substitutions examined, simulated increases in electronic media use were consistently associated with lower self-esteem (higher Rosenberg scores), with only a small number of non-significant predicted differences. We also observed an association between electronic media use and increased depression symptomology, but this was confined to a small number of specific behavioural substitutions. Our findings align with a previous analysis in this sweep of the MCS, which reported adverse associations of social media, internet use, TV viewing and video gaming with depressive symptomology and self-esteem. ${ }^{46}$ These studies add to a growing body of research examining the link between mental health and electronic media use, both traditional (eg, TV viewing) and contemporary (eg, social media) ${ }^{47-50}$ At present, the evidence appears equivocal, with findings sensitive to variations in measurement methodology and analysis. ${ }^{48}$ Given the cross-sectional nature of this analysis, findings should be interpreted with caution due to the possibility of reverse causality or bidirectional associations. Nonetheless, this study adds to the evidence on this topic by making explicit the interconnectedness of behaviours within the daily time budget and adopting an analytical framework that can accommodate this complexity. As the evidence evolves, this approach may become increasingly valuable as we move beyond the largely exploratory nature of existing studies towards research that can explicitly inform the targeting and content of public health policy and behaviour change interventions.

In our post hoc analyses, we examined the shape of the association between physical activity, electronic media use and selected mental health markers, informed by the findings from our primary analysis (figures 1 and 2). The size of the association between physical activity and MFQ, SDQ or Rosenberg scores varied according to whether our simulation added or removed time spent active. Specifically, predicted differences for a reduction in physical activity were approximately twice as large as those for an increase in physical activity; this was the case for all outcomes. This asymmetrical phenomenon has also been reported in other studies that have used compositional isotemporal substitution modelling, though it is not observed across all health 


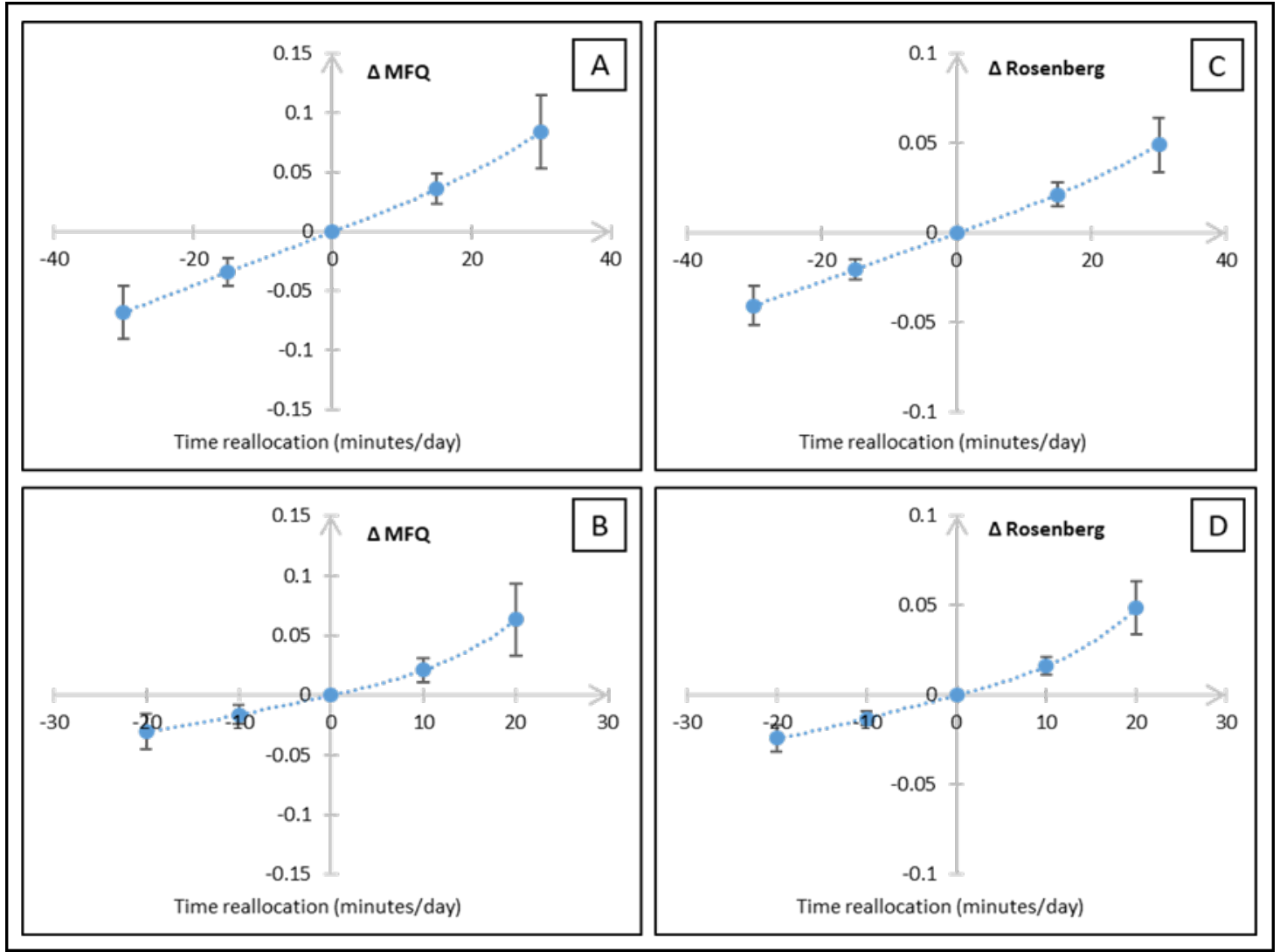

Figure 2 Predicted difference in Mood and Feelings Questionnaire and Rosenberg Self Esteem Questionnaire scores with selected time reallocations to/from electronic media use. MFQ, Mood and Feelings Questionnaire; Weekday data: panels A, C. Weekend data: panels B, D. Descriptive statistics (median (inter-quartile range)): MFQ: 17.0 (14.0, 21.0); RSE: 10.0 (7.0, 10.0). Models adjusted for age, sex, body mass index and family income. Data points are predicted differences in the outcome \pm standard error. Interpretation: Points plotted to the left of the Y-axis denote predicted differences in the outcome for a specified reduction in electronic media. Points plotted to the right of the Y-axis denote predicted differences in the outcome for a specified increase in electronic media.

outcomes $^{29} 31$ and was not evident in our models simulating multiple time reallocations for electronic media use. The reason for the disparity in effect sizes in our study is unclear, though it is appropriate to note that effect sizes remained small in all instances. It may reflect a plateau effect in the health benefits of physical activity, such that most benefit is gained from a moderate amount of activity and further increases above this level bring diminishing returns. This is consistent with the wider physical activity literature, particularly in adults, but the median activity level in the current sample was approximately $40 \mathrm{~min} /$ day, well below the recommended $60 \mathrm{~min} /$ day for this population. ${ }^{51}$ As more research using compositional analytical techniques emerges, it will be possible to describe and investigate this trend in greater depth and establish whether it is a reflection of biological, statistical or some other underlying process.

A key limitation of the current study is the cross-sectional design, which precludes any conclusions about the direction of the associations observed. The isotemporal substitution model mimics within-person time reallocations but remains a between-person comparison due to there being only one observation (point of assessment) per person. The findings are most appropriately interpreted as showing small differences in mental health status across durations of daily time allocated to physical activity and/or electronic media use. Numerous mental health conditions have lethargy or lack of engagement or energy within their diagnostic criteria ${ }^{52}$; therefore, reverse causality remains a highly plausible explanation for the associations observed in this study. In general, predicted differences in the weekend analysis were greater than those in the weekday analysis, which may also support this interpretation. Specifically with regard to physical activity, a larger proportion of weekday activity is nonvolitional in nature, shaped by the more structured nature of the school day and associated routines. ${ }^{45}$ This is reflected in evidence that the age-related decline in physical activity is smaller for weekdays than at the weekend and that weekday activity is less susceptible to seasonal variation. ${ }^{53}$ It follows that a reduction in physical activity associated with mental ill health is likely to be greater at the weekend than during the week. This may account, in part, for our observation of a stronger association between physical activity and socioemotional health at weekends versus during the week.

\section{Strengths and limitations}

Keys strengths of this study include the large, geographically and demographically diverse sample and the assessment of multiple mental health outcomes using well-established, 
widely tested instruments. In addition, daily activity was characterised in detail using 24-hour time-use diaries. Concurrent analysis of multiple behavioural exposures is appropriate given that behaviour change inherently entails the reallocation of time between different domains of behaviour. The following limitations are acknowledged. The cross-sectional design precludes causal inference and the possibility of reverse causality or bidirectional associations is acknowledged, as discussed previously. The analytical sample differed in its social and anthropometric characteristics compared with those who did not provide sufficient data to be included in the analysis, which may limit the generalisability of our findings. Statistical models were adjusted for known demographic and anthropometric confounders, but residual confounding is possible due to measurement error or omission of unknown confounding variables. In addition, we did not explore non-linear associations in the current analysis; this would be valuable in future research, particularly with regard to the sleep dimension of time use. Time-use diaries, like other self-report instruments, are susceptible to recall and social desirability bias. Lastly, our analysis is based on a single day of assessment, which may not be representative of typical behaviour patterns. However, measurement days were selected at random and short periods of assessment are typical in studies that employ time-use diaries in order to limit participant burden. ${ }^{36}$

\section{CONCLUSION}

This study adds to existing evidence on the association between lifestyle behaviours and mental health in adolescents. Our finding that substituting time from behaviours representing a number of different domains into physical activity was associated with better socioemotional health has important implications for intervention design, and should be examined further in longitudinal and experimental studies.

\section{Author affiliations}

${ }^{1}$ School of Health Sciences, Faculty of Medicine and Health Sciences, University of East Anglia, Norwich, UK

${ }^{2}$ Norwich Medical School, Faculty of Medicine and Health Sciences, University of East Anglia, Norwich, UK

${ }^{3}$ Alliance for Research in Exercise, Nutrition and Activity, Allied Health \& Human Performance, University of South Australia, Adelaide, South Australia, Australia ${ }^{4}$ Health Research Institute and Department of Sport and Physical Activity, Edge Hill University, Ormskirk, UK

${ }^{5}$ Department of Psychology, University of Liverpool, Liverpool, UK

${ }^{6}$ Department of Psychology, University of Winchester, Winchester, UK

\section{Twitter Richard Tyler @RP0Tyler}

Acknowledgements The authors are grateful to the participating families of the Millennium Cohort Study, the Centre for Longitudinal Studies, UCL Institute of Education, for the use of these data and to the UK Data Service for making them available.

Contributors AA conceived the research question, contributed to the statistical analysis and led on the manuscript preparation. JD conducted the statistical analysis, generated the figures and contributed to drafting segments of the Methods and Results sections. DD contributed to the development of the research question and advised on the statistical analysis and interpretation of the results. EK contributed to preparation of the Introduction and Discussion sections and the interpretation of the results. LS contributed to the development of the research question, the analytical approach and interpretation of results. RT contributed to the development of the research question and interpretation of the results. CR, RN and SF contributed to the development of the research question, the analytical approach and interpretation of results. All authors provided critical feedback on drafts of the manuscript and approved the final manuscript.

Funding This work was supported by a Child Development Research Grant from the Waterloo Foundation (Grant ref: 1669-3509). Elli Kontostoli is partially supported by an Academy of Medical Sciences/the British Heart Foundation/the Government Department of Business, Energy and Industrial Strategy/the Wellcome Trust Springboard Award (SBF003\1015) held by Dr Andrew Atkin. Additional funding from the University of East Anglia, Faculty of Medicine and Health Sciences, is gratefully acknowledged. DD is supported by the National Health and Medical Research Council (Australia) APP1162166 and the Heart Foundation (Australia) ID102084. The sixth sweep of the Millennium Cohort Study was core-funded by the Economic and Social Research Council (ESRC) and cofunded by the following consortium of government departments: Department for Education, Department of Health, Ministry of Justice, Home Office, Department for Transport, Department of Work and Pensions, Welsh Government and Department for Employment and Learning (Northern Ireland). The development of the MCS time diary instruments was supported by the ESRC Centre for Longitudinal Studies Resource Centre 2010-2015 grant (award number: RES-579-47-0001), as well as the ESRC Millennium Cohort Study Sweep 6 (Age 14) Survey grant (award number: ES/K005987). Supplemental funding was received from the ESRC cross-investment grant Children's time use diaries: promoting research, sharing best practice, and evaluating innovations in data collections internationally (award number: ES/F037937) that was a partnership between the Centre for Time Use Research at the University of Oxford and the Centre for Longitudinal Studies at the Institute of Education, University College London.

Competing interests None declared.

Patient consent for publication Not applicable.

Ethics approval MCS6 was approved by the National Research Ethics Service Research Ethics Committee, London-Central (REC ref: 13/L0/1786).

Provenance and peer review Not commissioned; externally peer reviewed.

Data availability statement The datasets analysed during the current study are available from the UK Data Service: beta.ukdataservice.ac.uk/datacatalogue/series/ series?id=2000031.

Supplemental material This content has been supplied by the author(s). It has not been vetted by BMJ Publishing Group Limited (BMJ) and may not have been peer-reviewed. Any opinions or recommendations discussed are solely those of the author(s) and are not endorsed by BMJ. BMJ disclaims all liability and responsibility arising from any reliance placed on the content. Where the content includes any translated material, BMJ does not warrant the accuracy and reliability of the translations (including but not limited to local regulations, clinical guidelines, terminology, drug names and drug dosages), and is not responsible for any error and/or omissions arising from translation and adaptation or otherwise.

Open access This is an open access article distributed in accordance with the Creative Commons Attribution Non Commercial (CC BY-NC 4.0) license, which permits others to distribute, remix, adapt, build upon this work non-commercially, and license their derivative works on different terms, provided the original work is properly cited, appropriate credit is given, any changes made indicated, and the use is non-commercial. See: http://creativecommons.org/licenses/by-nc/4.0/.

\section{ORCID iDs}

Andrew J Atkin http://orcid.org/0000-0002-3819-3448

Jack R Dainty http://orcid.org/0000-0002-0056-1233

Dorothea Dumuid http://orcid.org/0000-0003-3057-0963

Elli Kontostoli http://orcid.org/0000-0003-4285-4808

Richard Tyler http://orcid.org/0000-0001-9756-5582

Robert Noonan http://orcid.org/0000-0001-9575-5729

Cassandra Richardson http://orcid.org/0000-0003-1208-6588

Stuart J Fairclough http://orcid.org/0000-0001-8358-1979

\section{REFERENCES}

1 UNICEF. Adolescent demographics, 2016. Available: https://data. unicef.org/topic/adolescents/demographics/ 
2 Patton GC, Sawyer SM, Santelli JS, et al. Our future: a Lancet commission on adolescent health and wellbeing. Lancet 2016;387:2423-78.

3 Patton GC, Olsson CA, Skirbekk V, et al. Adolescence and the next generation. Nature 2018;554:458-66.

4 Viner RM, Ross D, Hardy R, et al. Life course epidemiology: recognising the importance of adolescence. J Epidemiol Community Health 2015;69:719-20.

5 Kessler RC, Amminger GP, Aguilar-Gaxiola S, et al. Age of onset of mental disorders: a review of recent literature. Curr Opin Psychiatry 2007;20:359-64.

6 Kessler RC, Berglund P, Demler O, et al. Lifetime prevalence and age-of-onset distributions of DSM-IV disorders in the National Comorbidity Survey Replication. Arch Gen Psychiatry 2005;62:593-602.

7 Paus T, Keshavan M, Giedd JN. Why do many psychiatric disorders emerge during adolescence? Nat Rev Neurosci 2008;9:947-57.

8 Erskine HE, Baxter AJ, Patton G, et al. The global coverage of prevalence data for mental disorders in children and adolescents. Epidemiol Psychiatr Sci 2017;26:395-402.

9 Pitchforth J, Fahy K, Ford T, et al. Mental health and well-being trends among children and young people in the UK, 1995-2014: analysis of repeated cross-sectional national health surveys. Psychol Med 2019;49:1275-85.

10 Page Z. CAMHS benchmarking 2016. NHS England, 2016. https:// www.nhsbenchmarking.nhs.uk/news/camhs-benchmarking-2016findings-published

11 Collishaw S. Annual research review: secular trends in child and adolescent mental health. $J$ Child Psychol Psychiatry 2015;56:370-93.

12 Kessler RC, Berglund P, Demler O, et al. Lifetime prevalence and age-of-onset distributions of DSM-IV disorders in the National Comorbidity Survey Replication. Arch Gen Psychiatry 2005;62:593-602.

13 Chaput J-P, Gray CE, Poitras VJ, et al. Systematic review of the relationships between sleep duration and health indicators in schoolaged children and youth. Appl Physiol Nutr Metab 2016;41:S266-82.

14 Carson V, Hunter S, Kuzik N, et al. Systematic review of sedentary behaviour and health indicators in school-aged children and youth: an update. Appl Physiol Nutr Metab 2016;41:S240-65.

15 Roberts RE, Duong HT. The prospective association between sleep deprivation and depression among adolescents. Sleep 2014;37:239-44.

16 Roberts RE, Duong HT. Is there an association between short sleep duration and adolescent anxiety disorders? Sleep Med 2017;30:82-7.

17 Mammen G, Faulkner G. Physical activity and the prevention of depression: a systematic review of prospective studies. Am J Prev Med 2013:45:649-57.

18 Kaneita Y, Ohida T, Osaki Y, et al. Association between mental health status and sleep status among adolescents in Japan: a nationwide cross-sectional survey. J Clin Psychiatry 2007;68:1426-35.

19 Dumuid D, Pedišić Željko, Stanford TE, et al. The compositional isotemporal substitution model: a method for estimating changes in a health outcome for reallocation of time between sleep, physical activity and sedentary behaviour. Stat Methods Med Res 2019;28:846-57.

20 PedišićZ, Olds TS, Dumuid D. Integrating sleep, sedentary behaviour, and physical activity research in the emerging field of time-use epidemiology: definitions, concepts, statistical methods, theoretical framework, and future directions. Kinesiology 2017;49:1-18.

21 Chaput J-P, Carson V, Gray CE, et al. Importance of all movement behaviors in a 24 hour period for overall health. Int J Environ Res Public Health 2014;11:12575-81.

22 Chastin SFM, Palarea-Albaladejo J, Dontje ML, et al. Combined effects of time spent in physical activity, sedentary behaviors and sleep on obesity and Cardio-Metabolic health markers: a novel compositional data analysis approach. PLoS One 2015;10:e0139984.

23 Aadland E, Kvalheim OM, Anderssen SA, et al. Multicollinear physical activity accelerometry data and associations to cardiometabolic health: challenges, pitfalls, and potential solutions. Int J Behav Nutr Phys Act 2019;16:74.

24 Dumuid D, Pedišić Željko, Palarea-Albaladejo J, et al. Compositional data analysis in time-use epidemiology: what, why, how. Int $J$ Environ Res Public Health 2020;17 doi:10.3390/ijerph17072220

25 Tremblay MS, Carson V, Chaput J-P, et al. Canadian 24-hour movement guidelines for children and youth: an integration of physical activity, sedentary behaviour, and sleep. Appl Physiol Nutr Metab 2016;41:S311-27.
26 World Health Organization. WHO guidelines on physical activity, sedentary behaviour and sleep for children under 5 years of age. Geneva, 2019. https://apps.who.int/iris/handle/10665/311664

27 Wong MY, Day NE, Luan JA, et al. The detection of geneenvironment interaction for continuous traits: should we deal with measurement error by bigger studies or better measurement? Int $J$ Epidemiol 2003;32:51-7.

28 Dumuid D, Olds T, Lewis LK, et al. Health-related quality of life and lifestyle behavior clusters in school-aged children from 12 countries. J Pediatr 2017:183:178-83.

29 Fairclough SJ, Dumuid D, Mackintosh KA, et al. Adiposity, fitness, health-related quality of life and the reallocation of time between children's school day activity behaviours: a compositional data analysis. Prev Med Reports 2018;11:254-61.

30 Wong M, Olds T, Gold L, et al. Time-Use patterns and health-related quality of life in adolescents. Pediatrics 2017;140 doi:10.1542/ peds.2016-3656

31 Carson V, Tremblay MS, Chaput J-P, et al. Associations between sleep duration, sedentary time, physical activity, and health indicators among Canadian children and youth using compositional analyses. Appl Physiol Nutr Metab 2016;41:S294-302.

32 Connelly R, Platt L. Cohort profile: UK millennium cohort study (MCS). Int J Epidemiol 2014;43:1719-25.

33 Ipsos MORI Social Research Institute. Millennium cohort study sixth sweep (Mcs6) technical report. prepared for the centre for longitudinal studies, UCL Institute of education 2017.

34 Ipsos MORI Social Research Institute. Millennium cohort study sixth sweep (Mcs6). Time use diary documentation. prepared for the centre for longitudinal studies, UCL Institute of education 2016.

35 Palarea-Albaladejo J, Martín-Fernández JA. zCompositions - R package for multivariate imputation of left-censored data under a compositional approach. Chemom Intell Lab Syst 2015;143:85-96.

36 Foley L, Dumuid D, Atkin AJ, et al. Patterns of health behaviour associated with active travel: a compositional data analysis. Int $J$ Behav Nutr Phys Act 2018;15:26.

37 Goodman R. The strengths and difficulties questionnaire: a research note. J Child Psychol Psychiatry 1997;38:581-6.

38 Noonan RJ. The effect of childhood deprivation on weight status and mental health in childhood and adolescence: longitudinal findings from the millennium cohort study. J Public Health 2019;41:456-61.

39 Noonan RJ, Fairclough SJ. Cross-sectional associations between body mass index and social-emotional wellbeing among differentially active children. Eur J Public Health 2019;29:303-7.

40 Thapar A, McGuffin P. Validity of the shortened mood and feelings questionnaire in a community sample of children and adolescents: a preliminary research note. Psychiatry Res 1998;81:259-68.

41 Rosenberg M. Society and the adolescent self-image. Rev. edn. Middletown, CT: Wesleyan University Press, 1989.

42 Cole TJ, Bellizzi MC, Flegal KM, et al. Establishing a standard definition for child overweight and obesity worldwide: international survey. BMJ 2000;320:1240-3.

43 Gerald van den Boogaart K, Tolosana-Delgad R, Matevz B. Compositions: compositional data analysis. R package version 1.40 2, 2018. Available: https://cran.r-project.org/package =compositions

44 Fox J, Weisberg S. An R companion to applied regression. London: Sage Publications, 2011

45 Rodriguez-Ayllon M, Cadenas-Sánchez C, Estévez-López F, et al. Role of physical activity and sedentary behavior in the mental health of preschoolers, children and adolescents: a systematic review and meta-analysis. Sports Med 2019;49:1383-410.

46 Twenge JM, Farley E. Not all screen time is created equal: associations with mental health vary by activity and gender. Soc Psychiatry Psychiatr Epidemiol 2021;56:207-17.

47 Orben A, Przybylski AK. The association between adolescent wellbeing and digital technology use. Nat Hum Behav 2019;3:173-82.

48 Twenge JM, Blake AB, Haidt J, et al. Commentary: screens, teens, and psychological well-being: evidence from three Time-Use-Diary studies. Front Psychol 2020;11:181.

49 Orben A, Przybylski AK, Screens PAK. Screens, teens, and psychological well-being: evidence from three Time-Use-Diary studies. Psychol Sci 2019;30:682-96.

50 Twenge JM, Campbell WK. Media use is linked to lower psychological well-being: evidence from three datasets. Psychiatr $Q$ 2019;90:311-31.

51 The Department of Health and Social Care. UK Chief Medical Officers' physical activity guidelines, 2019. Available: https://www. gov.uk/government/publications/physical-activity-guidelines-ukchief-medical-officers-report

52 American Psychiatric Association. Diagnostic and statistical manual of mental disorders. DSM 5. 5th edn. Arlington, VA: American Psychiatric Association, 2013. 
53 Atkin AJ, Sharp SJ, Harrison F, et al. Seasonal variation in children's physical activity and sedentary time. Med Sci Sports Exerc 2016;48:449-56.
54 Corder K, Sharp SJ, Atkin AJ, et al. Change in objectively measured physical activity during the transition to adolescence. $\mathrm{Br} J$ Sports Med 2015;49:730-6. 